\title{
A COREOGRAFIA DO BATUQUE E O CANTO NA INSTÂNCIA DO FANTÁSTICO/INSÓLITO: CORPOS AFRICANOS
}

\author{
Batuque: The identity in the bodies
}

Roselene de Fátima Coito (UEM- Gpleiadi-CNPq)

RESUMO: Michel Foucault, ao abordar os usos da História como o uso paródico da realidade, o uso dissociativo da identidade e o uso sacrificial da verdade, leva-nos a refletir sobre o que é a História sob a ótica da genealogia, a qual revela que a origem tal qual se concebe tradicionalmente, ou seja, linearmente, é questionável enquanto uma verdade atribuída por um conhecimento (ou um querer-saber) que percorre a humanidade. Este querer-saber de onde viemos e para onde vamos, tem suscitado reflexões variadas sobre identidade, sobre História e sobre verdade. No entanto, o que é a identidade quando se lhe atribui um caráter genealógico? O filósofo francês, partindo de Nietzsche, propõe dois olhares para esta discussão: a emergência ou o ponto de surgimento como possibilidade de reflexão sobre a origem, cujo termo em alemão é Entestehung, ou o corpo como "superfície de inscrições dos acontecimentos", cujo termo em alemão é Herkunft. É partindo deste segundo olhar, que discutiremos a coreografia do batuque, uma dança africana, acompanhada de musica, que traz em sua manifestação coreográfica o elemento místico/mágico/fantástico e o canto popular como práticas que instituem e constituem a identidade do africano que veio habitar o Brasil. Podemos dizer que a coreografia desta dança africana revela que o corpo e o canto falam e, que ao falarem, mostram-se numa compreensão de um outro lugar do dispositivo do saber, lugar este que, por não estar calcado numa ciência positivista se institui como a instãncia do místico/mágico/fantástico e que constitui a identidade africana marcada no corpo e na voz, principalmente deste momento histórico em questão - colonização - da nação brasileira.

PALAVRAS-CHAVE: Coreografia; Canto; Fantástico/Insólito; Corpos africanos. 


\title{
A COREOGRAFIA DO BATUQUE E O CANTO NA INSTÂNCIA DO FANTÁSTICO/INSÓLITO: CORPOS AFRICANOS
}

\begin{abstract}
Michel Foucault, approaching the uses of History as mimetic use of reality, dissociate use of identity and sacrificial use of truth, lead us to reflections about what History means, if considered on a genealogical point of view. Genealogy discloses that origin - understood as something linear (traditional point of view) - is questionable as a truth attributed by a knowledge (or a "want-to-know") that ranges over humanity. This "want-to-know" about our origin and our destiny has stimulated diverse reflections on identity, history and truth. Nevertheless, what means identity when one attributes to it a genealogical character? The French philosopher - on the basis of Nietzsche - presents two explanations to this discussion: the emergency or point of emergency as a possibility for the reflection about origin, (German: Entstehung) or the body as "a surface of events inscriptions" (German: Herkunft). Thinking about identity in body as "surface of events inscriptions" that us discuss batuque, an African dance with music, as a choreographic manifestation that bring the mystic/magic/fantastic element and the popular chant as a practice that establish and constitute a African's identity from habited in Brazil. We can talk that the choreography by these African dance revel that the body and the chant, booths, speak and show int the other comprehension of the other place of Know 's dispositive, place that, in other order, out positivist science, establish as mystic/magic/fantastic's instance and constitute the African identity marked in the body and the voice, especially in this historic moment - colonization - in Brazilian nation.
\end{abstract}

KEYWORDS: Choreography; Chant; Fantastic/Unusual; Africans bodies. 


\section{Introdução}

Neste artigo temos como pretensão discutir como o fantástico/o insólito, enquanto instância(s) que se dá (dão) no discurso, aparece(m) e/ou se materializa(m) na coreografia de uma dança africana chamada de batuque. Mesmo sabendo da complexidade do que possa ser o fantástico e o insólito - gênero, modalidade - não nos ateremos, neste momento, nesta especificidade do termo, embora seja bastante relevante. Então, preferimos adotar a palavra instância do fantástico/insólito. Pensaremos tal instância como constitutiva de uma etnia e, também, de, como diria Foucault, uma epistême que predomina em determinada época e sociedade. E como tal, esta instância materializada põe em evidência mais do que "o como o sujeito se vê", pois ao se instituir no saber de uma determinada época, a instância do fantástico e do insólito desvelam como o outro - aquele que não sou eu, me vê, e ao não se reconhecer em mim, trava uma relação de forças e de poder. Além disso, nesta relação que não está só no discurso, mas também no corpo como discurso, a dança em sua coreografia e o canto como modo de ver e se ver no mundo, marcam na sua simetria e em sua circularidade o mágico. Partindo desta prerrogativa é que propomos a discussão sobre a coreografia do batuque, dança africana, que daremos destaque nesta reflexão, e o canto do negro como um "complemento" deste entrelaçar do se ver e de ver o outro num campo de uma determinada epistemologia de saberes.

Na nossa proposta, faremos um recorte geográfico sobre esta coreografia, tendo em vista que houve, em várias regiões do Brasil, a presença dos africanos, que para cá foram trazidos como escravos. Aqui focalizaremos esta questão no território do interior do Estado de São Paulo, Brasil.

Batuque é uma dança de origem africana, como já fora dito, e no Estado de São Paulo, nos dias atuais, é dança de terreiro. Esta dança vem acompanhada de instrumentos musicais, os quais são: os membranofônios (tambu, quinjenje ou mulemba) e os idiofônios (matraca e guaiá); antigamente, o cordofônio (urucungo). A zona batuqueira paulista localizava-se no vale médio Tietê, abrangendo alguns municípios como Tietê (capital da zona batuqueira), Porto Feliz, Laranjal, Pereiras, Capivari, Botucatu, Piracicaba, Rio Claro, São Pedro, Itu, Tatuí. Em Campinas era chamado 
Caiumba, assim o registrou Carlos Gomes. Em Botucatu, até 1920 havia batuques no Largo do Rosário, no dia 13 de maio. Em São Carlos eram famosos os batuques do Cinzeiro, o bairro do Bola Preta, por causa da população negra e pobre que ali residia. Não passava mês sem batuque que de sábado ia a domingo quando o sol raiava, de acordo com Alceu Maynard Araújo (1997).

Não é possível afirmar com certeza qual grupo negro introduziu o batuque em São Paulo pelo fato de o canto não possuir palavras de origem africana, o que demonstra que esta dança, cantada e coreografada, pertence a um grupo mais "abrasileirado", pois os grupos com raízes bastante tradicionais tinham danças de roda e o canto apresentava palavras africanas. Num estágio mais adiantado, do ponto de vista coreográfico, o batuque se apresentava em duas colunas que se defrontavam e consistiam em dar umbigadas. Já, os cantos eram músicas cantadas que traziam o coro, o cordel e o desafio numa confluência de vozes híbridas por causa do abrasileiramento africano.

\section{O místico/mágico como epistême da similitude e como entendimento do funcionamento da instância do fantástico/insólito na cultura africana}

A dança batuque ritualizava a procriação. É sabido que na filosofia oriental, o umbigo é um canal energético (chacra) relacionado às emoções e à sexualidade, e como tanto, as tribos negras quanto as indígenas perpetuam em seus rituais ligações com a natureza, em seu mais pleno sentido. Isso nos leva a crer, que o saber, pensando em termos foucaultianos, instituído também como um saber popular, revela-se, na cultura negra como epistême da similitude. De acordo com o filósofo francês Michel Foucault, o homem e natureza são uma aparência de semelhança, que se dá no nível do pensamento. Contudo, na simbiose da semelhança enquanto uma prática do pensamento, ou seja, enquanto uma experiência vivida, o homem e a natureza são uma simbiose. É nesta semelhança e nesta simbiose que se pode pensar o Mesmo e o Outro. Aqui focalizaremos a simbiose enquanto uma experiência vivida, enquanto uma prática que instaura e se instaura na instância do fantástico/insólito.

Michel Foucault, em As palavras e as coisas, projeto no qual se propõe a refletir sobre uma arqueologia das ciências humanas, traz à baila a prática ocidental de se pensar o Mesmo e o Outro. Para tanto, parte da leitura de um texto de Jorge Luis Borges no qual o autor estabelece, por meio de uma taxinomia, a catalogação de animais, funcionando 
como uma semiologia em face da história e definindo a lei geral dos seres e, ao mesmo tempo, as condições sob as quais é possível conhecê-los. Diz o filósofo francês que, “[...]O impossível não é a vizinhança das coisas, é o lugar onde elas poderiam avizinhar-se". (FOUCAULT, 2000, p. 11).

O texto de Borges inquieta Foucault porque traz uma nova perspectiva do olhar; traz as heterotopias da linguagem. E, indaga-se Foucault: Onde mais estas coisas poderiam se alojar se não fossem na linguagem?, já que durante toda idade clássica

\footnotetext{
havia uma coerência entre a teoria da representação e as teorias da linguagem e, a partir do século XIX a teoria da representação desaparece como fundamento geral de todas as ordens possíveis [ e ] a linguagem como quadro espontâneo primeiro das coisas, como suplemento entre a representação e os seres, desvanece-se. (FOUCAULT, 2000, p. 20)
}

Estas colocações de Foucault devem-se à historização que o filósofo faz da epistême desde o século XVI sobre a questão "como reconhecer a representação em signo?".

Diz ele que no século XVI era por meio da semelhança. Neste século, os signos tinham sido depositados sobre as coisas e a semelhança se liga à imaginação, às repetições incertas e às analogias nebulosas; no XVII por meio da linguagem que vivia da transparência e da neutralidade, sendo o signo constituído pelo conhecimento o que difere o homem do animal; e, no século XVIII, pela máthésis e pela taxinomia, sendo que da máthésis tem-se a ciência da medida e da ordem em que o instrumento não é o método algébrico mas o sistema de signos, e da taxinomia o saber dos seres na sua identidade e diferença, em que há a dissociação entre signo e a semelhança.

É este jogo entre a semelhança - instituída pelo pensamento - e a similitude encontrada na experiência - que se instaura um reconhecimento da representação em signo, no caso aqui discutido, coreográfico do batuque como uma instância taxionômica, se se pensar que nesta coreografia, há no ritual um elemento místico/mágico em relação ao signo que constitui a linguagem desta dança africana numa razão que, perante à cultura europeia, dá-se como desrazão, nos termos epistemológicos foucaultianos, ou ainda, arriscaríamos a dizer, dentro das discussões que se desenvolvem sobre o fantástico, do insólito entre a cultura africana e a europeia quando da vinda dos africanos para o Brasil.

Sobre esta questão complexa que se desenvolve com relação ao fantástico, Pierini (2016, s/p) assevera: 


\title{
A COREOGRAFIA DO BATUQUE E O CANTO NA INSTÂNCIA DO FANTÁSTICO/INSÓLITO: CORPOS AFRICANOS
}

\begin{abstract}
O que temos diante de nós é, portanto, um imbróglio terminológico. No caso do insólito, tema deste artigo, autores como Bernard (1971), Guiomar (1957), Boucharenc (2011) e Komandera (2010), referem-se etimologicamente ao insólito como vindo do latim, insolitus, que quer dizer "incomum", "inusitado" e até mesmo insolens, "insolente" (aquele que não tem o hábito ou o costume de), ambos os termos saídos da mesma raiz, solere, "ter o costume", compartilhando tanto o sentido de "iniquidade" quanto de "excesso", ou seja, "contravenção dos usos e costumes e da sanidade lógica".
\end{abstract}

Tendo em vista que, a relação que se estabelece entre ciência e arte a partir de um momento histórico das sociedades, em que o filósofo Nietzsche põe em evidência no seu livro O nascimento da tragédia, muito grosso modo, como a cultura ocidental "elimina" Dionísio em favor de Apolo, do grotesco ao sublime, da escuridão à luz, respectivamente, "sobrou", na cisão que foi feita entre ciência e arte, à arte e/ou às manifestações artísticas o lugar em que "a contravenção dos usos e costumes e da sanidade lógica" a materialização do fantástico, do realismo mágico, do insólito, enfim daquilo que não se coloca naquilo que se tem como razão numa determinada época e sociedade. Contudo, como ainda propõe Pierini (2016, s/p), ao abordar a complexa discussão entre o gênero fantástico e/ou o gênero insólito:

\begin{abstract}
A considerar a minuciosa pesquisa de Raymond Trousson (1993), tanto o realismo mágico da pintura quanto o da literatura europeia ou latinoamericana possuem origens históricas, ideológicas e políticas diversas tanto entre si quanto em comparação ao fantástico ou ao insólito como buscamos encontrar neste trabalho. Provavelmente Guiomar conseguiu captar o surgimento do insólito antes mesmo que ele pudesse ser mais comodamente diferido do fantástico, que lhe é precedente, e do realismo mágico literário, que é seu contemporâneo.
\end{abstract}

Pensando nestas origens históricas, "ideológicas" e políticas na pintura e na literatura, ou melhor, nas artes e/ou manifestações artísticas em geral, podemos dizer que há elementos do fantástico, do mágico, do místico que são recorrentes na humanidade e que ora são reconhecidas como signos aceitos que prevalecem na sociedade e ora como signos menos comuns ou inusitados, os quais se dão na instância do fantástico e/ou insólito.

Tomando esta recorrência numa rede de relações, esta coreografia africana e o conto Ômphale, de Théophile Gautier[1], focalizam o umbigo como lugar da materialização do mágico.

Resumidamente, no conto de Gautier, Ômphale que faz referência à rainha da Ásia Menor narrada na mitologia grega, aquela que tinha o domínio, principalmente, sobre os homens pelo seu poder de inteligência estratégica e de sedução[2][3], no conto, 
publicado pela primeira vez em 1834, cujo subtítulo é "Ônphale - A Tapeçaria amorosa", ela, Onfale, está representada em uma tapeçaria no quarto de um jovem adolescente. Em determinadas noites, ela se destaca do quadro e o seduz. Tal como a rainha da Ásia Menor da mitologia grega, à referência a esta rainha no quadro, como a própria tradução do seu nome em grego, preconiza que o umbigo é o lugar em que o elemento mágico, inusitado, evidencia-se. Assim, também, a coreografia do batuque consiste num ritual de umbigadas, trazendo à tona esta rede de sentidos estabelecidos com relação à força da natureza.

Nesta coreografia ritualizada, também há o traço místico/mágico relacionado ao número três: "Após três umbigadas, o homem procura batucar com outra mulher". O três relaciona-se tanto ao sacro quanto ao profano. Ao sacro, quando remete ao discurso religioso da Santíssima Trindade: Pai, Filho e Espírito Santo, ou todos em um só; ao profano, tomando o profano como uma ciência desvalorizada na cultura ocidental, e mais especificamente, na forma de ver da ciência positivista, relacionado à filosofia oriental do equilíbrio (ou o caminho do meio) e à geometria esotérica do triângulo equilátero simbolizando o equilíbrio. Portanto, neste jogo de similitude, a cultura negra desvela-se, mais uma vez, como uma comunhão plena entre o homem e a natureza. Isso muito incomodou a visão da igreja, a qual via (e ainda predomina esta visão) o homem como imagem e semelhança de Deus como uma entidade de perfeição transcendente, impedindo o homem de ver-se na natureza ou ver na natureza uma aparência de semelhança consigo. Em outras palavras, o homem reprimindo seus instintos e elevando-se à categoria de ser assexuado.

A coreografia desta dança africana trazia aos fazendeiros donos de escravos e à Igreja um desconforto, uma inquietação e uma reprovação com relação aos costumes e à moral da sociedade brasileira da época. Muitas vezes, os donos de fazenda faziam "vistas grossas" para tais manifestações do batuque, porque acreditavam que se os escravos africanos pudessem se divertir um pouco, produziriam mais no dia seguinte. Então, por questões econômicas e de exploração permitiam que se divertissem. Contudo, o poder da Igreja era determinante também e se mostrava numa relação de forças com os fazendeiros e preconizavam a imoralidade da dança e sua demonização, que era uma forma de privar o negro que veio da África de sua identidade, pois conforme Nietzsche "o homem só pode ser completamente livre ao integrar-se voluntariamente aos impulsos típicos da terra" (apud Barrenechea, 2000). 


\section{A COREOGRAFIA DO BATUQUE E O CANTO NA INSTÂNCIA DO}

FANTÁSTICO/INSÓLITO: CORPOS AFRICANOS

Pensando, então, nesta outra maneira de entendimento do que é a razão que se dá entre as diferentes culturas e na predominância da epistême de uma determinada época e de uma determinada sociedade, o ritual coreográfico desta dança lança a possibilidade de se propor o elemento - e como o elemento - do fantástico como aquilo que "revela uma estética da conjunção dos improváveis e das contradições" e que "conjuga o real e o irreal", conforme Prince (2008, p. 16 e 29). Ainda conforme a autora (2008, p. 16),

le fantastique est le récit du surgissement d'un surnaturel ou d'un irrationnel pour soi, c'est-à-dire pour une conscience, dans un ordre naturel et rationnel normatif qui constituait l'ordinaire de cett conscience. Le fantastique pousse cette conscience à produire l'hypothèse paradoxale de la possibilité d'un impossible... [4]

Tomando, então, nas devidas proporções daquilo que se entende como fantástico, a coreografia como uma narrativa de um irracional diante de uma racionalidade positivista instituída, onde o fantástico se submete a uma variável cultural, já que traz em sua prática um "acontecimento escandaloso" - o ritual da procriação que promove "a inquietude e o questionamento", (PRINCE, p. 36), tendo em vista que, no ritual da dança há elementos culturais que envolvem a visada mística - pontos energéticos do corpo, o número de vezes dos umbigos se encontrando, é que o discurso sobre o sexo se revela fortemente interditado.

\section{Discurso sobre o sexo é interditado}

Segundo Foucault, um dos mecanismos de controle externo sobre o sujeito é a interdição do discurso sobre o sexo.

Como não poderia deixar de ser, pelo fato de o batuque estar ligado à sexualidade, a igreja abominou, interditou dizeres e práticas de algumas danças, dentre elas, o batuque, considerada uma dança sensual e muito ligada à prostituição da senzala, já que os preceitos cristãos de moralidade vêem no sexo o pecado, tanto que a tentação de Eva e Adão é uma metáfora do descobrimento do sexo, o que provocou a expulsão de ambos do paraíso. Essa metáfora, que perdura até hoje, é um dos mecanismos de controle sobre o próprio corpo, isto é, o não-conhecimento de si.

No entanto, no relato de Maynard Araújo sobre a cultura popular brasileira, o senhor da senzala ignorou a interdição da igreja e isso fez com que o ritual do batuque chegasse até nossos dias, o que faz com que pensemos que o discurso da sexualidade, 
não em uma visão religiosa, sofre interdição, principalmente nesta época e nesta sociedade, mais por um problema político-social do que propriamente religioso. Isso se deve ao fato de que não é mais a Igreja quem determina a conduta dos sujeitos sociais, mas a política-social e econômica. Portanto, o silêncio dos senhores dos escravos não é uma discordância do discurso da Igreja, mas uma estratégia para conseguir mais mãode-obra escrava, confirmando a citação de Eni Orlandi em As formas de silêncio:

O silenciado tem uma materialidade histórica presente nos mecanismos de funcionamento dos discursos e em seus processos de significação. Daí, podemos concluir que: na reprodução já há não-reprodução, na censura já há resistência, na interdição dos sentidos já estão os sentidos outros, naquilo que não foi dito está o trabalho do sentido que virá a ser. Em suas várias formas e modos que só a história pode assentar. Assim, não há censura completamente eficaz: os sentidos escapam e pegam a gente a seu modo. $(1997, \mathrm{~s} / \mathrm{d})$

Conforme vimos na citação de Orlandi, "o silenciado tem uma materialidade histórica presente nos mecanismos de funcionamento dos discursos e em seus processos de significação", e o fato de discurso de Maynard apontar para a questão do silenciamento dos senhores de escravos, é uma estratégia discursiva que revela a prática como um poder que predomina no momento: não é mais a igreja quem detém o poder, mas os donos de fazendas de café, os quais mantinham os negros sob sua tutela. Contudo, podemos dizer que há um jogo nesta relação de poder: os senhores silenciam, a igreja proíbe e os negros praticam. Se por um lado há resistência por um motivo político - senhores contra a igreja - por outro há uma resistência para auto-afirmar uma identidade - a coreografia da dança batuque praticada pelos negros. E é sobre isso que trataremos no item seguinte.

\section{Coreografia: a representação do mágico como a constituição da identidade marcada no discurso do corpo}

Como já foi apontado anteriormente, batuque é uma dança africana que foi trazida pelos escravos na época da colonização do Brasil. A coreografia da dança remetia à integração do homem com a natureza, natureza esta que integra movimentos corporais na possibilidade do mágico intervir na procriação humana e, ao mesmo tempo, na constituição e/ou reafirmação da identidade deste povo em questão, pois que uma das formas de se pensar a constituição de uma identidade de um povo, segundo Michel 
Foucault, respaldado em Nietzsche, é o corpo, ou melhor, a identidade inscrita nos corpos.

Esta dança se coreografava da seguinte maneira: uma fileira é de homens, junto aos instrumentos musicais que ficam pousados no solo e defrontando-a fica a de mulheres. Estão separadas uma da outra cerca de dez a quinze metros, espaço onde dançam, dando umbigadas. Um batuqueiro não dança sempre com a mesma batuqueira. Após três umbigadas procura batucar com outra.

No batuque não há batidas de pés, tão comuns nas danças de origem ameríndia. Há umbigadas. Quando um batuqueiro, defrontando sua dama, entre uma umbigada e outra, faz meneios de corpo, ajoelha-se, mas sempre dentro do ritmo ditado pelo tambu, a estes movimentos chama de "jongar". Os batuqueiros mais jovens dão habilíssimos rodopios nestas figurações como o pião-parado, o corrupio.

Ao amanhecer, quando vai findando o batuque, a "dança saideira" é o "leva-etraz". O cavalheiro faz vênia, não dá "batidas" ou umbigadas, vai levar a dama no seu lugar inicial, como que fechando um ciclo da energia que foi movimentada no percurso da coreografia. A representação gráfica desta dança e dos instrumentos nela utilizados, podem ser vistos logo abaixo:

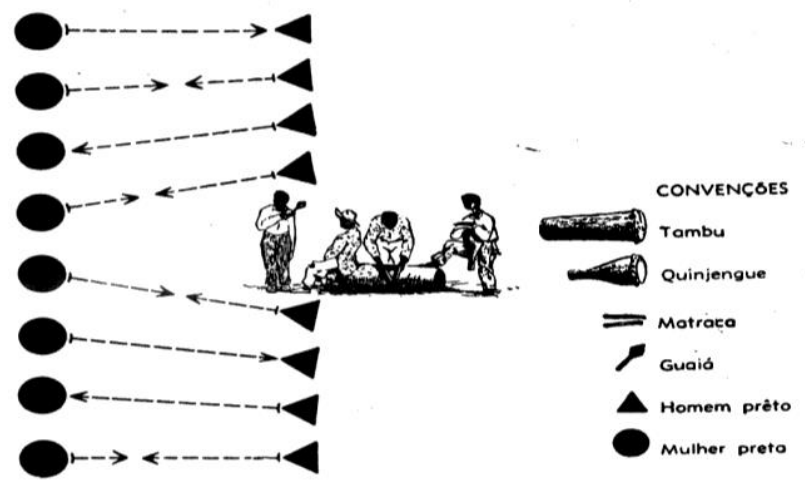

Figura 1. Alceu Maynard Araújo (1997, p. 38).

Como dissemos acima, esta dança não é circular como dos africanos e dos ameríndios, e sua simetria pressupõe uma ação do homem com relação à mulher, isto é, o homem se dirige à mulher para o ato do ritual da procriação e embora o branco europeu veja nesta prática um ato profano, o negro a confirma (a prática) como um ato sagrado. Dito de outro modo, o ato da procriação e a prole são dádivas concedidas por Deus, já que a esterilidade é uma maldição. Neste sentido, também, pode-se estabelecer uma relação com o texto bíblico, se levarmos em consideração a passagem bíblica em 
que Jesus amaldiçoa a figueira e a mesma se torna estéril. Portanto, o branco europeu vê na sexualidade algo proibido porque se fixa na passagem bíblica da expulsão de Adão e Eva do paraíso e o negro na dádiva que são os filhos concebidos. É certo que o ritual da sedução, para uma tradição judaico-cristã, é visto como uma prática profana, já que esta tradição vê o homem como imagem e semelhança de Deus e não o homem como similitude da natureza. Ou melhor, o homem e a natureza em plena simbiose.

No prefácio do livro Linguagem, identidade e memória social, Ferreira e Orrico (2002, p. 8) dizem que: "independentemente das motivações subjacentes à cultura da memória, as práticas revelam a necessidade de novas ancoragens que permitam a reavaliação entre passado, presente e futuro". Pensando na coreografia do batuque, instituída como acervo do folclore brasileiro, e ainda praticada em rituais da umbanda, podemos dizer que ao reavaliarmos o passado por meio desta prática - a dança -, encontramos a identidade negra, marcada no e pelo corpo, como um meio de resistência à interdição da igreja, mesmo quando podemos interpretar a reafirmação do texto bíblico na prática da dança, e resistência ao aculturamento africano, mesmo quando há traços afro-brasileiros na cultura africana reelaborada. Dito em outros termos, quando não há mais a circularidade no ritual da dança, tendo em vista que a circularidade também remete a elementos mágicos, e quando não há no canto, palavras de origem africana. Isso fica evidente no canto negro que destacaremos no próximo item.

O canto negro: discurso da vida no fato acontecido - confluência da voz popular: coro, cordel e desafio

Um batuqueiro "modista" faz "poesia" ou "décimas". Outras vezes, cantando em determinada "linha", em dado momento quando os demais encontram uma boa trova, "suspendem o ponto", isto é, começam a repetir aquela quadra ou "linhada dupla de versos".

Há diferenças entre "modista" e "carreirista". Os bons batuqueiros são a um só tempo "modista-carrerista". O "modista" é cantador de décimas. Estas são as modas sobre um "fato acontecido". Quando um modista canta uma décima, todos ficam parados ouvindo - o. O cantador de "carreira" em geral não canta "moda", mas somente porfia com o outro. Canta uma quadra em determinada "carreira", ou "linha", e o adversário responde: 


\section{A COREOGRAFIA DO BATUQUE E O CANTO NA INSTÂNCIA DO \\ FANTÁSTICO/INSÓLITO: CORPOS AFRICANOS}

Levantei de madrugada

Fui passeá no meu jardim,

Achei falta de uma rosa

E um botão de alecrim.

Resposta do "carreirista" oponente:

Amanhã alevante mais cedo

Antes do cuitelo vim,

Vá pega o passarinho

Que feiz isso pra ti.

O "modista", após a moda, coloca o "ponto" motivo de canto e dança. Canta uma quadra, quando todos estão seguros, tanto nas letras como na melodia, o "carreirista" ou "modista", pois qualquer um deles pode colocar o "ponto", cantará dois versos e os demais batuqueiros cantarão os dois restantes da quadra fixada após a consulta coletiva. O solista canta:

o amor que não é firme eu comparo que nem boi.

Os demais, em coro, completam: põe um homem na cadeia,
ninguém sabe porque foi.

Com podemos ver neste canto, além do hibridismo da composição formal do texto (coro - típico da cultura popular grega aos nossos olhos ocidentais -, cordel e desafio - bastante comuns no nordeste brasileiro, vindos da tradição portuguesa), vemos o processo cultural da transformação histórica do Brasil, ou seja, a cultura afro desenhando um novo ritmo e uma nova concepção de se olhar o homem, até mesmo pela proximidade da linguagem do canto estar calcada na oralidade.

Esta marca de oralidade, muito comum em cantos populares, são registros do hibridismo cultural pelo qual o negro brasileiro se constituiu. No primeiro canto, cujo tema é a relação do homem com a natureza, marca a sintonia que há entre o dizer do homem negro e do homem do campo, isto é, pelo uso das palavras, principalmente cuitelo, a qual significa beija-flor no linguajar caipira, de acordo com o Dicionário Aurélio. Esta palavra nos permite ver a marca histórica do analfabetismo tanto do negro quanto do branco europeu que em terras brasileiras veio trabalhar, resguardando as diferenças do processo histórico de cada qual. Contudo, a relação com a natureza não é a mesma entre os povos. Dito de outro modo, mesmo mantendo uma relação de simetria 
pelo processo híbrido desta "nova" identidade que vai surgindo, agora pela voz, que constitui o corpo em sua sonoridade, e não pelo movimento dos corpos, o africano atribui à natureza, no caso, o cuitelo, a responsabilidade de o amado não poder presentear a amada com uma rosa. Contudo, este amor não é idealizado como um amor romântico de uma tradição europeia artística burguesa.

Quanto à moda, o tema é universal: o amor, como já dissemos. O tema do amor, nesta moda, não é o do amor romântico, mas de um amor oscilante que pode provocar uma tragédia. Se compararmos as cantigas trovadorescas de amigo e de amor com relação a esta moda, a situação amorosa na visão do negro está mais próxima do real do que do ideal do amor, que é traço característico da não-ocidentalização africana, se pensarmos que, depois da cristianização do ocidente, o amor entre um homem e uma mulher se dá na instância da transcendência de Maria e José. Um amor sublime e de elevação, não carnal.

Se a estrutura linguístico-poética tanto da carreira quanto da moda se aproximam da estrutura linguístico-poética greco-latina, os temas não. Isso marca o hibridismo no qual os africanos e os afro-descendentes constituíram e constituem sua identidade, o que nos leva a considerar que a identidade de um povo não é algo fixo e imutável, mesmo quando há traços particulares que permitem diferenciar uma etnia da outra, mas que são sentidos moventes construídos ao longo da(s) história(s). Neste sentido, a movência desta constituição da identidade, mesmo com hibridismos culturais, resguardam e marcam a instância do mágico, do místico, do fantástico e do insólito, como pudemos perceber.

\section{Considerações finais}

O que pretendemos mostrar com esta breve reflexão é que um dos usos da história, adotando a reflexão de Foucault, é dissociar sistematicamente identidades. E, neste sentido, trazer o fantástico/insólito como instâncias, as quais se constituem e que constituem uma determinada epistême, revela o quanto a instauração do saber não se desvincula de uma relação de poder. Isso é o que vemos quando a Igreja quer impedir a manifestação do batuque e quando os senhores donos de escravo fazem "vista-grossa" para tal manifestação. Se a Igreja, com sua visão de moralidade, quer impedir a dança, para os senhores de escravos, ela, a dança, é o caminho que produzirá mais mão-de-obra escrava. Portanto, não é um princípio de humanitarismo de ambas as partes, mas é sim 
um questão política, social e econômica. Por isso, Foucault, segundo Paul Veyne, revoluciona a história. Ele não vê o objeto e sim a prática destes objetos da história e o que está por trás da interdição ou liberação desta prática. É o que ele toma como governamentabilidade no e do ato político.

Contudo, a governamentabilidade destes corpos negros manipulados, modelados, treinados e obedientes ao e no processo da escravidão e da exclusão social, tidos pelo poder dos senhores de fazendas como corpos de homens-máquina, cria uma representação do negro como um ser domesticável. No entanto, esta falsa representação que a história insiste em determinar como corpo domesticável, é "desmentida" no momento em que o negro resiste à domesticação e instaura um novo dizer: o dizer da/na dança e do/no canto: o dizer da liberdade de corpos que movimentam a história revelando que os sentidos, também da identidade que se constitui por meio do corpo e da voz, estão na dispersão e, também, nos silenciamentos.

Além disso, trazer à reflexão não só como os signos se dão a reconhecer em determinadas epistême, épocas e sociedades, mas como cada etnia reconhece o seu signo e nele se reconhece, revela como os sujeitos se posicionam no mundo e diante dele, sendo que, a instância do fantástico e/ou do insólito permeia tudo aquilo que nos inquieta, aquilo que nos amedronta - por ser inusitado e diferente -, aquilo que nos revela como sujeitos contraditórios e, ao mesmo tempo, mostra-nos como somos prisioneiros de valores sociais impostos quando somos pre-determinados por saberes que se constituem numa razão positivista, que exclui aquilo que, naquele momento histórico, naquela época e naquela sociedade está fora "da ordem do discurso" vigente.

Por fim, podemos dizer que trazer à tona a diferença entre os povos e entender que esta diferença, que no nosso caso, inscreve-se nos corpos por meio da coreografia, põe em xeque a razão e a verdade, o real e o fantástico, todos como uma instância de uma contínua movência, de flutuações e de inquietações.

\section{Referências}

ARAÚJO, Alceu Maynard. Cultura Popular Brasileira. 3 ed. São Paulo: Melhoramentos, p. 63-81, 1997.

COITO, Roselene de Fatima. A ilustração: da representação como interpretação do simbólico. Revista da ABRALIN, v. 14, p. 149-169, 2015. 
FERREIRA, Lucia M. A \& ORRICO, Evelyn G. D. (orgs.). Linguagem, Identidade e Memória Social - Novas Fronteiras, Novas articulações. Rio de Janeiro: DP\&A, 2002.

FOUCAULT, Michel. Microfísica do Poder. 18 ed. Org e trad. Robert Machado, Rio de Janeiro: Edições Graal, 1979.

. Isto não é um cachimbo. Trad. Jorge Coli. Rio de Janeiro: Paz e Terra, 1998.

. A ordem do discurso. Trad. Laura Fraga de Almeida Sampaio. 5. ed. São Paulo: Loyola, 1999b.

As Palavras e as Coisas: uma arqueologia das ciências humanas. Trad. Salma T.

Muchail. São Paulo: Martins Fontes, 2000.

GAUTIER, Théophile. Omphale - histoire rococo - "La mort amoureuse e Le pied de momie". Trad. Walderedo Ismael de Oliveira. Rio de Janeiro: Imago, 2001.

LERMEN, Núlvio. A árvore da vida- do místico ao quântico. Acesso: 29 ago. 2016.

NIETZSCHE, Friedrich. O nascimento da tragédia ou Helenismo e Pessimismo. Trad. Notas e Pósfácio J. Guinsburg. São Paulo: Companhia das Letras, 1992.

ORLANDI, Eni P. As formas do Silêncio: no movimento dos sentidos. 4. ed. Campinas: Ed. Unicamp, 1997. (Coleção Repertórios).

PIERINI, Fábio Lucas - Do insólito como gênero narrativo. 2016 (no prelo)

PRINCE, Nathalie. Le fantastique. Ed Armand Colin, Paris, 2008.

VEYNE, Paul. Foucault revoluciona a história. 4 ed. Brasília: UnB, 1998.

www.quesiagracez.com/2013/04/rainha-onfale-dominador.html. Acesso: 29 ago. 2016.

Recebido em 08/12/2016

Aceito em 18/02/2017. 